\title{
TIME-RESOLVED RESONANCE RAMAN SPECTROSCOPY OF THE LOWEST EXCITED TRIPLET STATE OF BENZIL
}

\author{
N. LOCOGE-KARBOWSKI, G. BUNTINX and O. POIZAT* \\ L.A.S.I.R., CNRS UPR A 2631 L, Université des Sciences et Techniques de Lille Flandres \\ Artois, Bât. C.5, F-59655 Villeneuve d'Ascq cedex, France \\ *L.A.S.I.R., CNRS UPR A 2631 T, 2 rue Henri Dunant, F-94320 Thiais, France
}

\begin{abstract}
The time-resolved resonance Raman spectrum of the first excited triplet state of benzil is reported in the range $400-1700 \mathrm{~cm}^{-1}$. A comparative vibrational analysis of the ground state and the triplet state is given, and structural implications are discussed.
\end{abstract}

Benzil is a representative molecule of the $\alpha$-dicarbonyls class which is extensively studied in reason of its interesting and diversified photophysical and photochemical properties $(1,2)$. It is also a typical photoinitiatior of radical polymerization $(3,4)$. Skewed (dihedral angle between the planes of the two carbonyl groups $\simeq 111^{\circ}$ in crystal) (5) and near-trans planar $(6,7)$ forms were found for the ground (So) and lowest triplet ( $\mathrm{T}_{1}$ ) states, respectively.

Resonance Raman spectroscopy with pulsed Laser excitation and multichannel optical detection is a very sensitive tool to detect transient species in solution and the analysis of vibrational spectra gives unique information about their molecular structure. We have used the pump-then-probe technique to analyse by resonance Raman spectroscopy the first triplet state (Ti) of benzil.

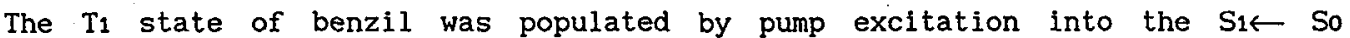
absorption band at $248 \mathrm{~nm}$ and $308 \mathrm{~nm}$ in conjunction with $\mathrm{T}_{1} \leftarrow \mathrm{S}_{1}$ intersystem crossing, and was probed at $483 \mathrm{~nm}$, i.e. in resonance with the visible $\mathrm{Tn}_{\mathrm{n}} \leftarrow \mathrm{T} 1$ absorption $(8,9)$. Excitations at 248 and $308 \mathrm{~nm}(20 \mathrm{~ns}, 2 \mathrm{~mJ})$ were obtained with an excimer Laser (questek 2040) : $\mathrm{KrF}$ and $\mathrm{XeCl}$ respectively. Probe excitation at $483 \mathrm{~nm}$ ( $8 \mathrm{~ns}, 1.5 \mathrm{~mJ}$ ) was achieved by pumping Coumarine 480 in a dye laser (Quantel TDL 50) with the third harmonic of a $10 \mathrm{~Hz}$ Q-switched Nd : Yag Laser (Quantel model YG $581 \mathrm{C}$ ).

Analysis of the transient Raman spectrum has been made by comparison with the ground state one. The same transient triplet spectrum was observed in methanol, acetonitrile, 2 propanol, cyclohexane and carbon tetrachloride. The assignments corresponding to the So and $T_{1}$ states are given in table 1 . These assignments have been confirmed by the analysis of the isotopic frequency shifts observed for two isotopic derivatives (benzil -D10, benzil - ${ }^{18} \mathrm{O}_{2}$ ) (10).

The main vibrational change observed on going from so to $T_{1}$ (table 1) is a considerable decrease of the CO stretching frequency $\left(\Delta v C O=-213 \mathrm{~cm}^{-1}\right)$ in accord with the $n \pi \pi^{*}$ nature of $\mathrm{I}_{1}$. Moreover one remarks an important increase of the stretching frequency of the intercarbonyl $\mathrm{C}-\mathrm{C}$ bond $\left(\Delta v \mathrm{CO}-\mathrm{CO}=+110 \mathrm{~cm}^{-1}\right)$ 
but, contrary to what was observed for benzophenone (11), the main ring modes $(8 a-19 a-12-1)$ remain only weakly disturbed.

This means that the electronic perturbation in triplet benzil is localized essentially on the dicarbonyl fragment. This perturbation can be summarized as resulting from a notable weakening of the $\pi$-character of the $C O$ bonds and a strengthening of the $\pi$-character of the intercarbonyl $\mathrm{CO}-\mathrm{CO}$ bond. The dominant intensity of the Raman band due to the intercarbonyl $\mathrm{C}-\mathrm{C}$ bond stretching underlines the highly symmetric character of this vibration. This point is strongly in favor of a trans conformation of this triplet species. The structure can thus be described by a delocalized form intermediate between the following configurations :

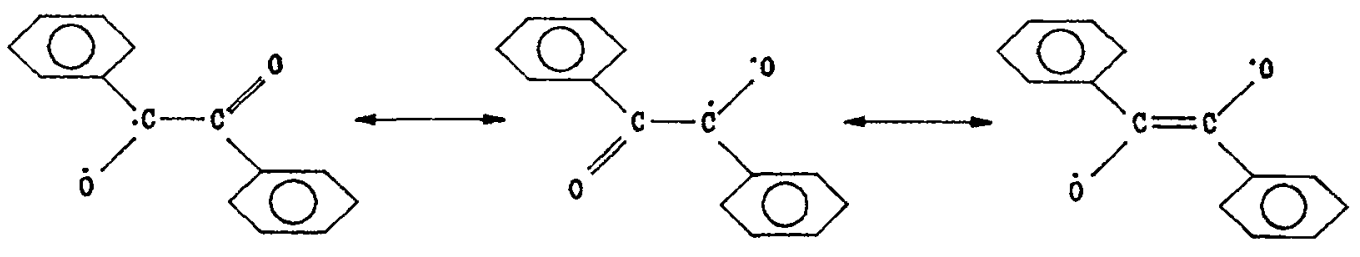

This conclusion is in agreement with the structural results reported by Chan and Heath (6) from electron nuclear double resonance experiments and by Fessenden and Col. (7) from transient microwave dielectric absorption measurements.

Note that, on the other hand, weakly enhanced transient Raman spectra ascribed to the ketyl radical and to the anion radical have been found (10) with probe excitation at $370 \mathrm{~nm}(9,12)$ for solutions containing hydrogen atom donors (alcohols : methanol, ethanol, 2-propanol) and electron donors (TEA) respectively.

Finally, another transient Raman spectrum has been detected (10) in acetonitrile solutions for high pump excitation energy $(248 \mathrm{~nm})$ and power, which is probably due to the radical product of cleavage : C6H5-CO, first observed from flash photolysis experiments $(1,13)$.

Table 1 : Raman frequencies $\left(\mathrm{cm}^{-1}\right)$ and assignments of the ground state (So) and triplet state ( $T_{1}$ ) spectra of benzil.

\begin{tabular}{|l|c|c|}
\hline Mode assignments & So & T1 \\
\hline C=0 stretching & $1676 / 1668$ & 1430 \\
8 a (ring CC stretching) & 1595 & 1580 \\
19a (ring CC stretching) & 1492 & 1480 \\
+ CH in plane bending & 1453 & 1457 \\
19b ? & 1176 & 1195 \\
$9 a$ (CH in plane bending) & 1048 & 1160 \\
CO-CO stretching & 1020 & 1030 \\
18a (CH in plane bending) & 1000 & 997 \\
12 (trigonal) & 700 & 984 (sh) \\
1 (ring breathing) & 616 & 501 \\
mixed CC + CO def & & \\
\hline
\end{tabular}




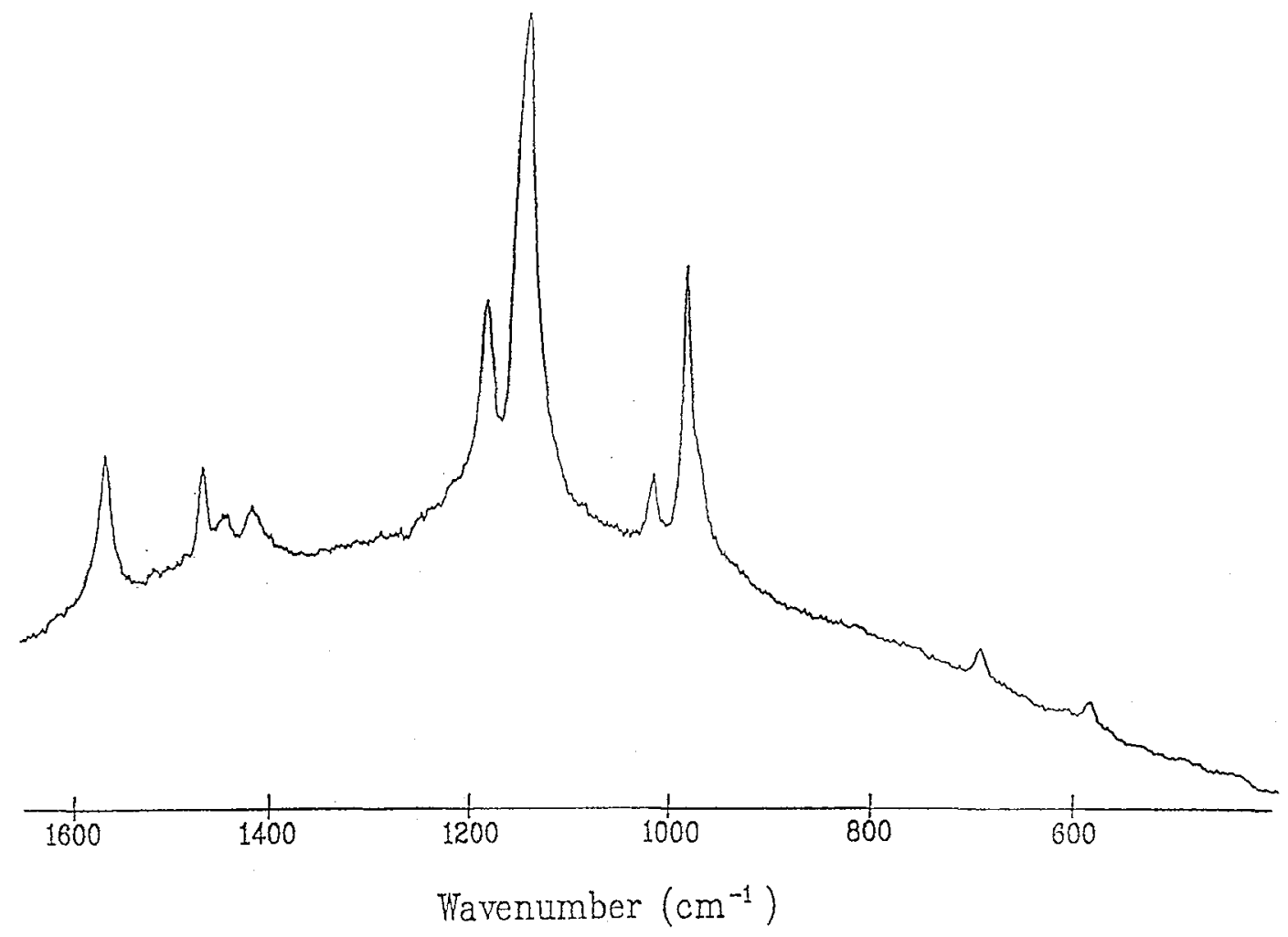

Fig.1 - Time-resolved resonance Raman spectrum (1700-400 $\left.\mathrm{cm}^{-1}\right)$ excited at $483 \mathrm{~nm}$ (pump at $248 \mathrm{~nm}$ ) of the $\mathrm{T} 1$ transient of benzil in deaerated $\mathrm{CCl}_{4}$ (solvant bands have been substracted).

\section{References :}

(1) Mc GIMPSEY, W.G., SCAIANO, J.C., J. Am. Chem. Soc. 109 (1987) 2179.

(2) MUKAI, M., YAMAUCHI, S., HIROTA, N., J. Phys. Chem., 93 (1989) 4411.

(3) LEDWITH, A., Pure and Appl. Chem., 49 (1977) 431.

LEDWITH, A., RUSSELL, P.J., SUTCLIFFE, L.H., J.C.S. Perkin II (1972) 1925.

(4) FOUASSIER, J.P., Makromol. Chem. Macromol. Symp., 18 (1988) 157.

FOUASSIER, J.P., JACQUES, P., LOUGNOT, D.J., PILOT, T., Polymer Photochem. 5 (1984) 57.

(5) BROWN, C.J., SADANAGA, R., Acta Cryst., 18 (1965) 158.

(6) CHAN, I.Y., HEATH, B.A., Chem. Phys, Lett., 46 (1) (1977) 164.

CHAN, I.Y., HEATH, B.A., J. Chem. Phys., 71 (13) (1979) 1070.

(7) FESSENDEN, R.W., CARTON, P.M., SHIMAMORI, H., SCAIANO, J.C., J. Phys. Chem., 86 (1982) 3803 .

(8) ENCINAS, M.V., SCAIANO, J.C., J. Am. Chem. Soc., 101 (1979) 7740.

(9) DAS MOHAPATRA, G.K., BHATTACHARYA, J., BANDOPADHYAY, J., J. Photochem. Photobiol., A, 40 (1987) 47.

(10) G. BUNTINX, N. LOCOGE, O. POIZAT (in preparation).

(11) TAHARA, T., haMaguCHI, H., TASUMI, M., J. Phys. Chem. 91 (1987) 5875.

(12) HAYON, E., IBATA, I., LICHTIN, N.N., SIMIC, M., J. Phys. Chem., 76 (15) (1972) 2072 .

(13) ENCINAS, M.V., GARRIDO, J., LISSI, E.A., J. Polym. Sci., Polym. Chem. Ed. 27 (1989) 139.f 